\title{
Biomechanical Investigation of Locked Plate Fixation with Suture Augmentation in a Comminuted Three-Part Proximal Humerus Fracture Model
}

\author{
Brian T. Palumboํ, Sergio Gutierrez ${ }^{2}$, Brandon Santoni' ${ }^{2}$, Mark Mighell ${ }^{1}$ \\ ${ }^{1}$ Florida Orthopaedic Institute, Tampa, USA \\ ${ }^{2}$ Foundation for Orthopaedic Research and Education (FORE), Tampa, USA \\ Email: mmighell@floridaortho.com
}

How to cite this paper: Palumbo, B.T., Gutierrez, S., Santoni, B. and Mighell, M. (2017) Biomechanical Investigation of Locked Plate Fixation with Suture Augmentation in a Comminuted Three-Part Proximal Humerus Fracture Model. Open Journal of Orthopedics, 7, 180-191. https://doi.org/10.4236/ojo.2017.77020

Received: March 30, 2017

Accepted: July 3, 2017

Published: July 6, 2017

Copyright $\odot 2017$ by authors and Scientific Research Publishing Inc. This work is licensed under the Creative Commons Attribution International License (CC BY 4.0).

http://creativecommons.org/licenses/by/4.0/

\begin{abstract}
Background: Locked plating of displaced proximal humerus fractures is a reliable fixation method. Greater tuberosity (GT) failure is a known complication that may occur in the early post-operative period. Despite postoperative immobilization, the rotator cuff continues to exert significant forces on fracture fragments. Our hypothesis is that suture augmentation will provide greater stability of the GT than locked plating alone. To prove this we developed a three-part proximal humerus fracture model to test fracture fixation. Methods: A biomechanical study was performed on nine fresh frozen cadaveric humeri, simulating a three-part proximal humerus fracture (Neer Classification). Rotator cuff tendon insertions were preserved to physiologically load the proximal humerus. The fracture was reduced and fixed with a locked plate alone or a locked plate with suture augmentation of the GT to the rotator cuff tendons. Biomechanical testing utilized a materials testing machine and a three-dimensional motion capture system to quantify interfragmentary motion under torsional loading as a function of fixation type. Results: Greater torsional stability was observed in the suture-augmented group compared to the plate only group $(p=0.0012)$. There were two catastrophic failures in the plate only group while none of the suture reinforced constructs failed. Conclusions: In our model, suture-augmentation of the GT to the rotator cuff provided greater stability than locked plating alone. The current study provides a biomechanical basis for reinforcing locked plate constructs with sutures. The added stability afforded by suture-augmentation may mitigate rotator cuff forces in the clinical setting, avoiding fracture displacement in the early postoperative rehabilitation period.
\end{abstract}




\section{Keywords}

Basic Science Study

\section{Introduction}

Proximal humeral fractures account for $4 \%$ to $8 \%$ of all fractures annually and are the third most common type in patients over 65 years of age [1]. Open reduction and internal fixation (ORIF) of displaced proximal humerus fractures is an accepted surgical technique [1]-[6]. Locked plate technology has emerged as a tool to improve fixation in osteoporotic bone and affords the surgeon the option of fixing fractures previously relegated to management by arthroplasty. In comparison to standard plating techniques, locked plating has resulted in improved outcomes in clinical and biomechanical studies [7] [8] [9] [10].

Failed fixation and displacement of the greater tuberosity (GT) in the early postoperative period may result in malunion, diminished range of motion, impingement and loss of shoulder strength and function [10]-[16]. Methods to stabilize the GT and counteract the deforming forces of the rotator cuff have been previously described [1] [5] [17]-[23]. Biomechanical evidence supports the current surgical strategies to prevent tuberosity failure when treating proximal humerus fractures [24] [25] [26] [27].

The purpose of this biomechanical study was to analyze the effects of suture augmentation of the GT in a three-part proximal humerus fracture construct fixed with a locked plate. The goal was to determine whether suture augmentation improves interfragmentary stability compared to locking plate fixation alone.

\section{Materials and Methods}

\subsection{Specimen Preparation}

Biomechanical testing was performed on nine fresh-frozen, cadaveric humeri obtained from eight donors (Science Care, Aurora, Co, USA) with a median age of fifty-nine years (range: 40 - 81). The median body mass index was $28.7 \mathrm{~kg} / \mathrm{m}^{2}$ (range: 17 - 29.5). Specimens were without a history of humeral fracture, tumor, infection or instrumentation.

The physiologic rotator cuff forces that are present even when wearing a sling were simulated in order to accurately assess the interfragmentary stability afforded by the two forms of internal fixation. We constructed a testing model that included the insertions of the rotator cuff muscles which were loaded similarly to their native force vectors, under previously described physiologic loads [28] [29] [30].

Proximal humeri were dissected to maintain the infraspinatus (ISP), supraspinatus (SSP) and subscapularis (SSC) tendons and a three-part fracture (Neer Classification) [31] of the proximal humerus was created. An osteotomy of the 
GT was performed $5 \mathrm{~mm}$ posterior to the bicipital groove and completed with the saw blade exiting at the perimeter of the SSP, ISP and teres minor tendon insertions [32] [33]. Care was taken to preserve the insertions in all specimens. We specifically intended to evaluate the integrity of fixation in a comminuted GT fracture model. To simulate this comminution in a standardized method a second osteotomy of the GT fragment was performed at its midpoint with an osteotome in the horizontal plane. The surgical neck fracture was then created with an oscillating saw perpendicular to the humeral shaft. Specimens were frozen at $0^{\circ} \mathrm{C}$ for storage and each was thawed twelve hours prior to testing. Fractures were reduced and fixed with a Synthes Proximal Humerus Internal Locking System (PHILOS ${ }^{\circledR}$ ) (Synthes, Inc., West Chester, PA). The device was implanted on the lateral aspect of the proximal humerus $0.5 \mathrm{~cm}$ posterior to the lateral edge of the bicipital groove. Six locked screws were placed proximally and three non-locking screws were placed into the shaft. Internal fixation of the GT fragment was achieved in each specimen.

The myotendinous junctions of the SSC, SSP and ISP were sewn with heavy, nonabsorbable suture in Krackow fashion. Size 2 metal rings (Essentials-South Bend, Northbrook, Illinois) were sutured to each of the tendons three centimeters proximal to the plate in the twelve and three o'clock positions for left sided constructs and twelve and nine o'clock positions for right sided plates. Two rings were placed into the suture holes of the plate in the twelve and three o'clock positions for left-sided plates and the twelve and nine o'clock positions for right-sided plates (Figure 1(a) and Figure 1(b)). Plastic tie straps were used rather than suture to eliminate bias that would be introduced if the sutures were hand tied. The tie straps were uniformly tensioned to $30 \mathrm{~N}$ as determined by a tensionmeter [24].

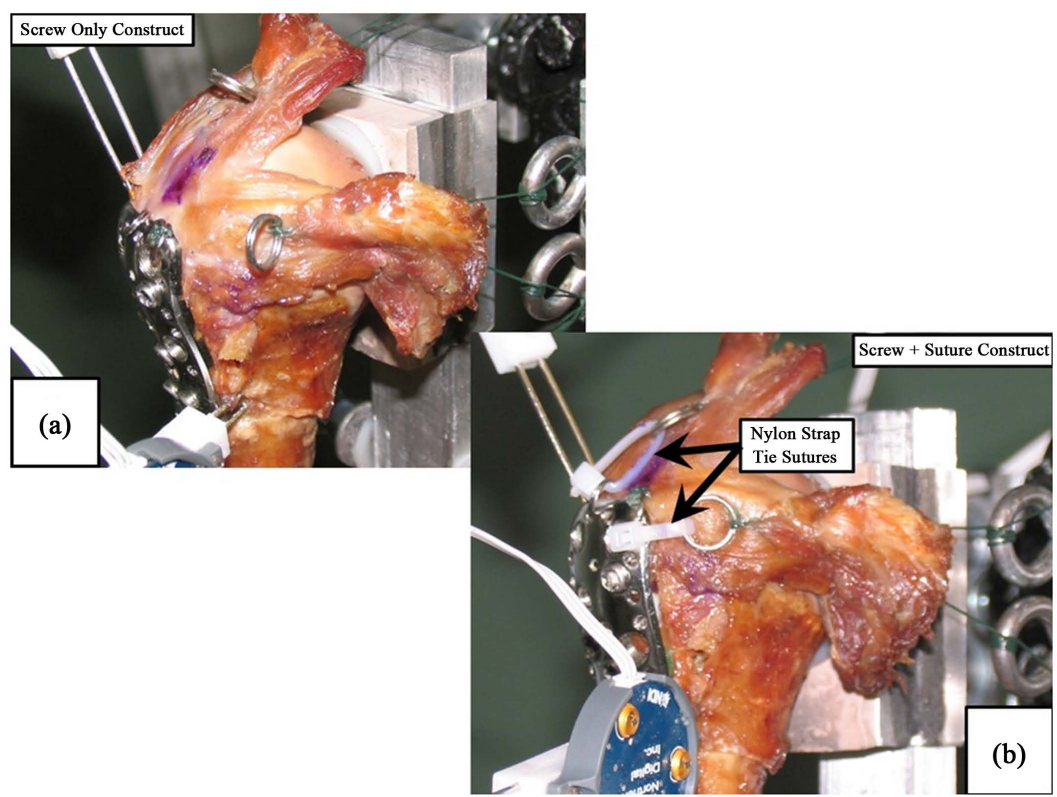

Figure 1. (a) Illustration of screw-only construct; (b) Illustration of screw and suture construct. 


\subsection{Specimen Fixation}

All humeri were cut nineteen centimeters distal to the humeral head. The distal aspect of the specimens was placed in a polyvinyl chloride (PVC) cylinder and then into a $120 \mathrm{~cm} \times 76 \mathrm{~cm}$ aluminum container. Vertical alignment of the shaft relative to the base was determined by centering the distal humeral shaft in the PVC cylinder with a micrometer. The humeral shaft/PVC construct was then secured to the aluminum container with screws and polymethylmethacrylate re$\sin$. Constructs were bolted to the base of the testing system in neutral rotation with the humeral head in contact with a rigidly fixed, total shoulder glenoid component (Figure 2).

\subsection{Experimental Setup}

Testing was performed using a servoelectric materials testing machine (Test Resources, Model $800 \mathrm{~L}$, Shakopee, MN) and a 3D motion capture system (Optotrak Certus ${ }^{\mathrm{mex}}$, Northern Digital, Inc., Waterloo, Ontario, Canada). The humeral shaft/PVC construct was rigidly attached to a torsion actuator and under load control of a $2.2 \mathrm{kN}$ axial load cell (Test Resources) attached to the ISP tendon (Figure 3). Individual, static forces applied to the remaining rotator cuff muscles were based upon previously published values observed in vivo [28] [29] [30]. The SSC was statically tensioned using a pulley and $6.77 \mathrm{~kg}$ of weight to simulate a force of $66.3 \mathrm{~N}$ in line with the muscle's vector of action [28] [29]. The SSP was statically tensioned using a pulley and $2.61 \mathrm{~kg}$ of weight to simulate a force of $25.6 \mathrm{~N}$ in line with the muscle's vector of pull. The torsion motor applied 2000 cycles of sinusoidal force to the ISP tendon, ranging from 5 to $66.3 \mathrm{~N}$ (applying a moment of 0.1 to $1.25 \mathrm{~N}-\mathrm{m}$ ) [30], at $1 \mathrm{~Hz}$ simulating contraction of both the

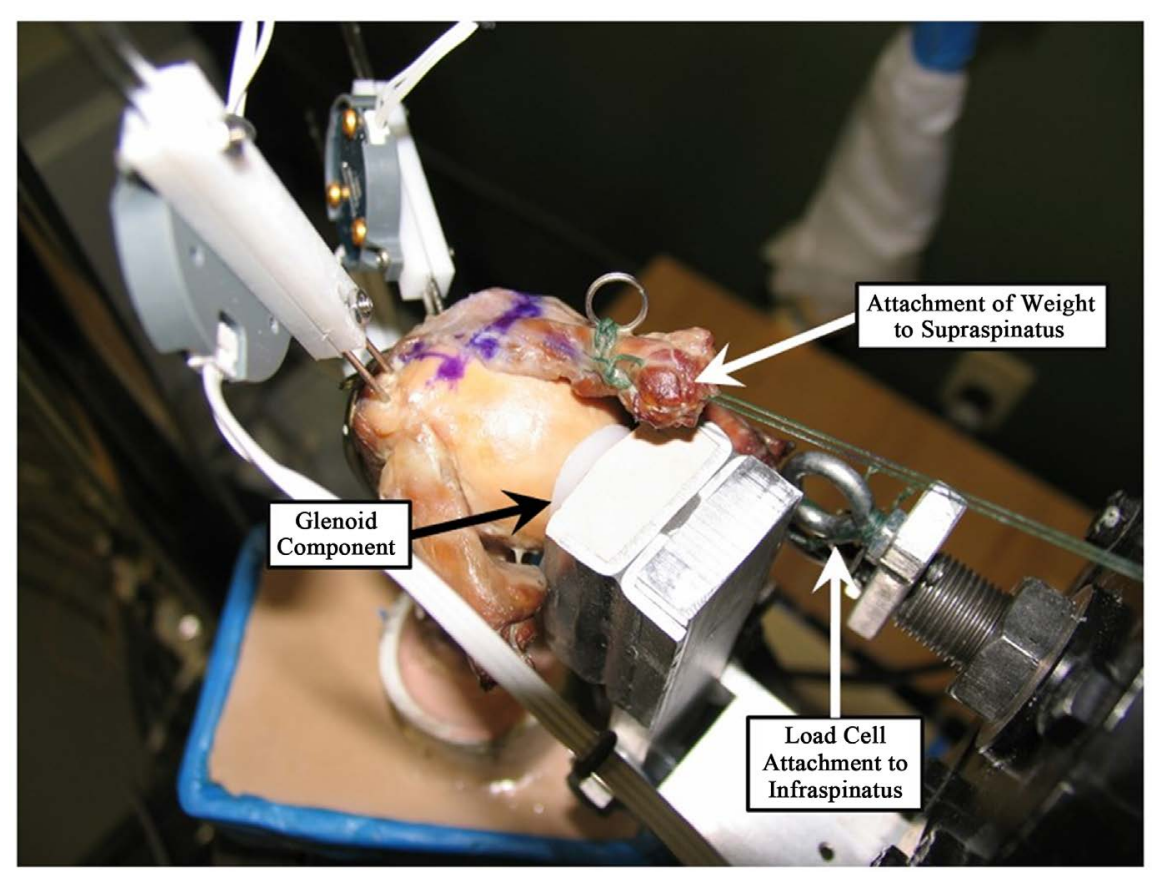

Figure 2. Illustration of testing configuration (superior view). 


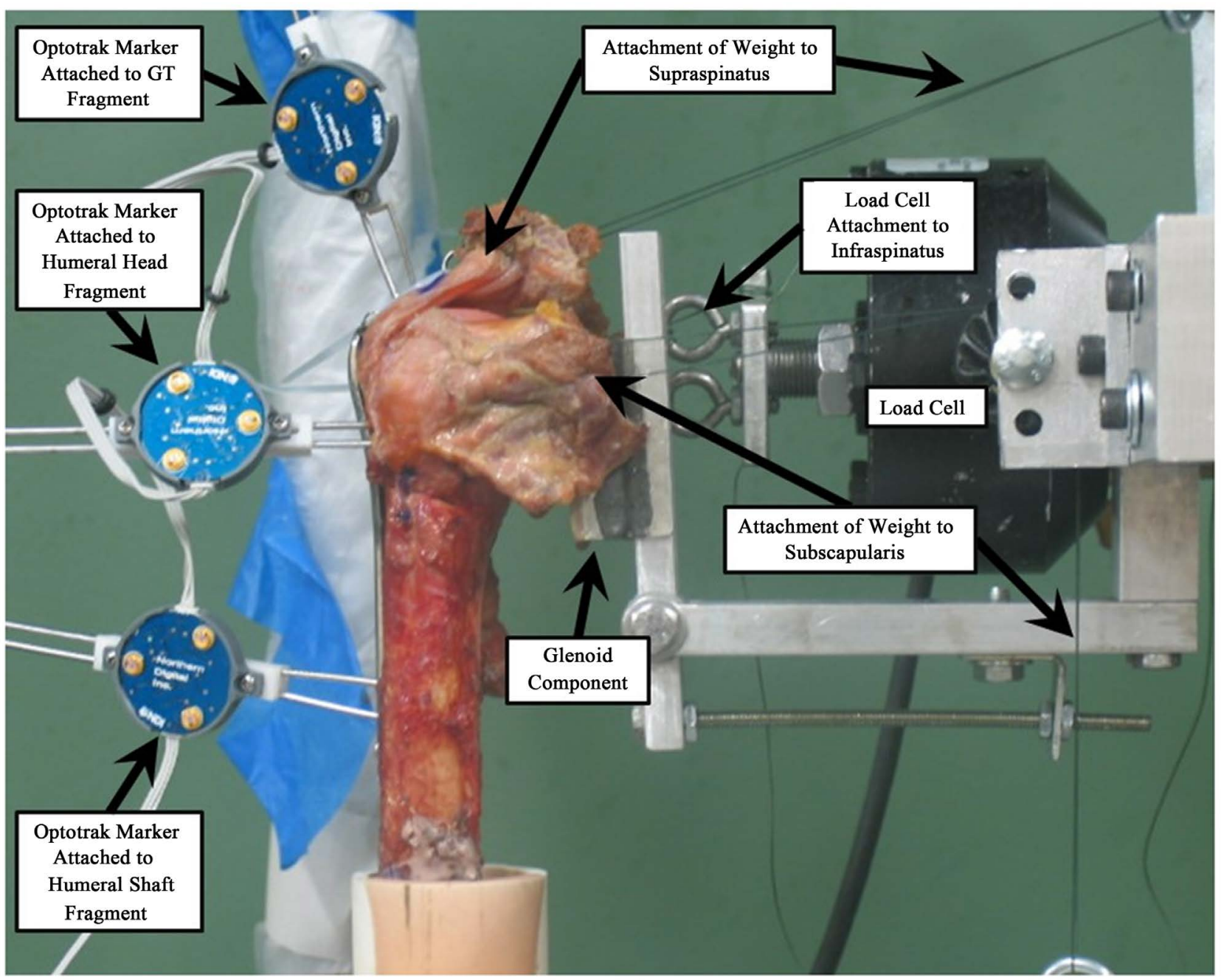

Figure 3. Illustration of testing configuration (anterior view).

subscapularis and infraspinatus tendons. The moment applied to the testing construct was calculated by multiplying the force applied to the ISP tendon by the torsion motor and the distance of the ISP insertion from the central axis of the humeral shaft. Optoelectronic LED marker triads (Northern Digital, Inc.) were rigidly attached to the humeral head, GT, and humeral shaft to quantify the relative rotations between the fracture fragments during cyclic, torsional loading of the repaired constructs. For the current study, interfragmentary stability was defined as the measured relative rotation between the GT and humeral head fragments and was calculated from the slope of the linear portion of the moment/angular displacement curve using the following equation:

$$
K=\frac{M}{\theta}
$$

where $K$ is the torsional stiffness $(\mathrm{N}-\mathrm{m} / \mathrm{deg}) ; M$ is the change in moment applied to the GT fragment $(\mathrm{N}-\mathrm{m})$; and $\theta$ is the relative change in angular displacement of the GT fragment relative to the humeral head $\left({ }^{\circ}\right)$ about a coordinate axis that was defined with the Optotrak system to be parallel to the central axis of the 
humeral shaft. Interfragmentary stability at time zero, and after 500, 1000, 1500 and 2000 cycles of loading was calculated for comparison between fixation groups. At each of these pre-defined intervals, the construct was loaded 5 times and the average $\mathrm{K}$ was derived and used for statistical comparison.

To mitigate the potential bias caused by testing sequence, specimens were randomly assigned to (1) locked plate (LP) alone testing first (Figure 1(a)) or (2) locked plate with suture augmentation (LPSA) testing first (Figure 1(b)). The two fixation configurations were tested with each specimen serving as their own control.

\subsection{Statistical Analysis}

Due to the failure of 2 of the specimens during testing, statistical analysis was performed with $\mathrm{n}=7$. Torsional stiffness data was initially screened for normality using the Shapiro-Wilk statistical test. As it was determined that all data sets satisfied the normality assumption, torsional stiffness data within each construct type were compared with a one-way repeated measure analysis of variance (ANOVA) with post hoc multiple comparison of groups using Bonferroni correction to determine the effects of cycle number (0,500,1000, 1500 and 2000) on construct rigidity. Differences in the measured torsional stiffness between the two forms of repair after 2000 cycles of loading were compared with a paired t-test. All analyses were performed using SPSS v.20 (IBM, Chicago, IL) at a significance level of 0.05 .

\section{Results}

There were two construct failures, both in the LP group. Both failures

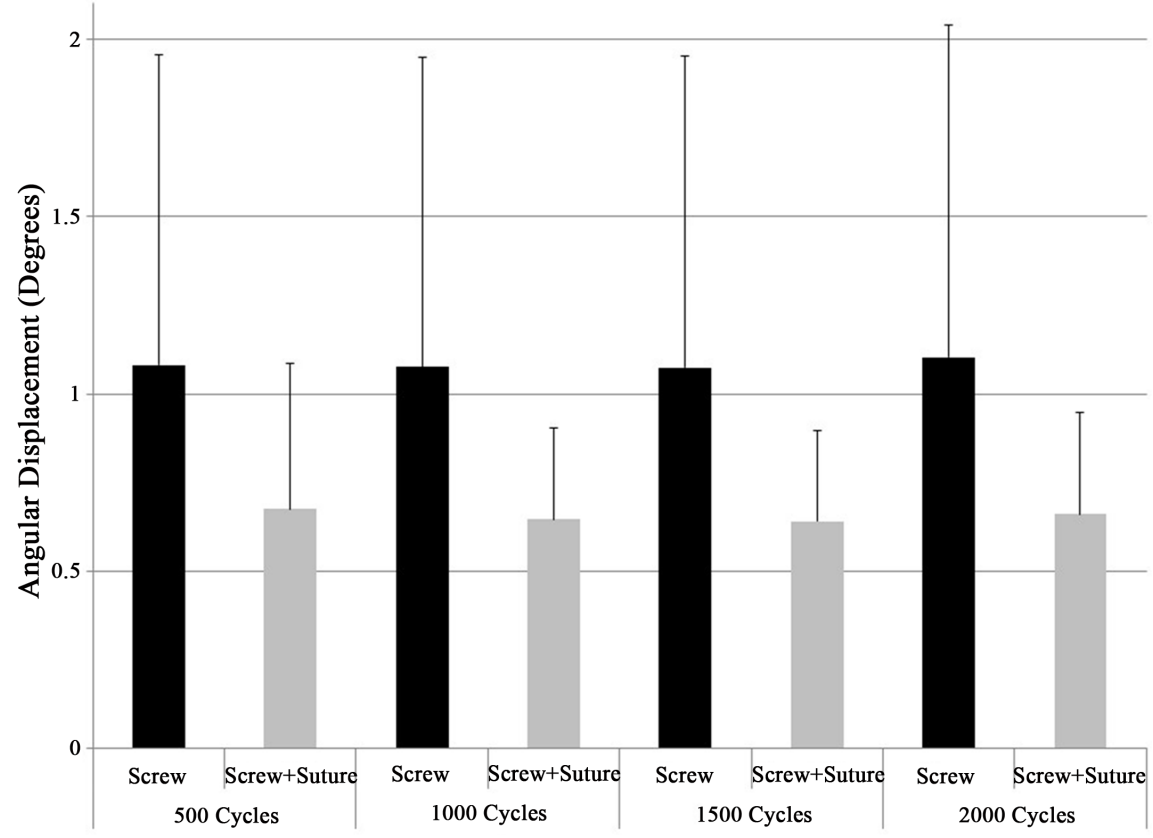

Figure 4. Comparison of angular displacement in screw only and screw and suture constructs. 
occurred within the first 1000 cycles of torsional loading. The GT avulsed from the remainder of the specimen in the first failure and the second specimen failed by gross motion of the humeral head fragment. The stiffness data from these two specimens were excluded from final statistical comparison.

Interfragmentary stability did not significantly change after 2000 cycles of loading for LP fixation (Baseline: $1.8 \pm 1.0 \mathrm{~N}-\mathrm{m} /{ }^{\circ} ; 2000$ Cycles: $1.8 \pm 0.9 \mathrm{~N}-\mathrm{m} /{ }^{\circ}$, $p=0.502$ ) or LPSA (Baseline: $2.4 \pm 1.2 \mathrm{~N}-\mathrm{m} /{ }^{\circ} ; 2000$ Cycles: $2.2 \pm 0.9 \mathrm{~N}-\mathrm{m} /{ }^{\circ}, p=$ 0.512). After 2000 cycles of loading the LPSA construct conferred, on average, $25.2 \%$ greater interfragmentary stability than the LP construct (Figure 4 and Figure 5). This difference was statistically significant $(p=0.0012)$ (Table 1$)$.

\section{Discussion}

Adequate GT stabilization is essential for good clinical outcomes in the treatment of displaced proximal humerus fractures. Fixation methods must counter rotator cuff forces to allow early initiation of shoulder rehabilitation while avoiding fracture displacement [15] [34]-[42]. Inadequate fixation and stability may lead to GT displacement and malunion in the early post-operative and rehabilitation periods [12] [14] [16]. Use of shoulder immobilizers does not completely negate interfragmentary strain and motion after operative fixation. Rotator cuff muscles continue to contract even when the shoulder is immobilized creating an environment of multidirectional strain and shear at the GT and surgical neck fracture interfaces [19] [20] [22] [43]. This is supported by electromyographic studies demonstrating contraction of the SSP, ISP and SSC muscles during contralateral upper limb motions [44].

The current study is a physiologic three-part proximal humerus fracture model that closely approximates the biomechanical milieu of the fracture fragments and the rotator cuff during the early post-operative period. It replicates the beginning of active internal and external rotation at the 4 - 6-week postoperative period. The LPSA construct demonstrated significantly greater torsional stiffness compared to locked plating alone. There were two catastrophic failures in the LP only group and occurred during the first 1000 cycles of torsional loading. In contrast, no failures occurred in the suture-augmented group. This biomechanical data set supports the concept that suture augmentation may work clinically to confer added stability to the greater tuberosity during proximal humerus fracture fixation.

Table 1. Average rotational micromotion and stiffness of screw only and screw and suture constructs.

\begin{tabular}{cccc}
\hline & Construct & All Cycles $(0-2000)$ & Statistical Significance \\
\hline $\begin{array}{c}\text { Rotational Micromotion } \\
\text { (Degrees) }\end{array}$ & Screw Only & $1.08 \pm 0.89$ & \\
$\begin{array}{c}\text { Rotational Micromotion } \\
(\mathrm{N}-\mathrm{m} / \text { Degree })\end{array}$ & Screw + Suture & $0.66 \pm 0.30$ & $p=0.0012$ \\
& Screw + Suture & $2.30 \pm 0.96$ & $p=0.0012$ \\
\hline
\end{tabular}




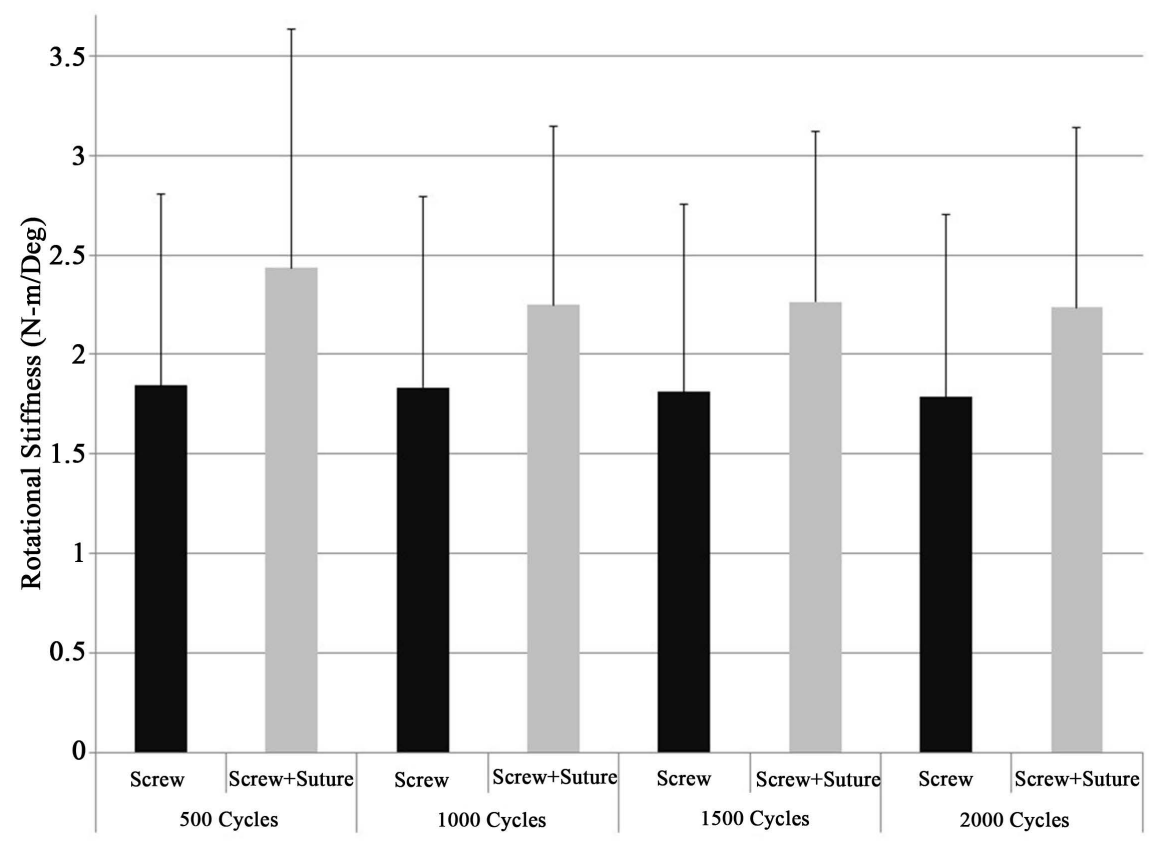

Figure 5. Comparison of rotational stiffness of screw only and screw and suture constructs.

Voigt et al. performed a similar biomechanical analysis evaluating the effects of suture augmentation of the GT in a three-part fracture model [15]. They also fabricated a testing construct that closely approximated in vivo forces of the shoulder and rotator cuff. Interestingly, they did not find a decrease in interfragmentary motion with suture augmentation and concluded that it did not improve stability of the GT. However, in their study, a single, stable osteotomy of the GT was performed which permitted its anatomic reduction and allowed for complete coverage with the PHILOS locking plate with multiple screws of fixation. In our experience, this scenario is seldom found in three-part fractures in elderly patients with osteoporotic bone. The GT is frequently comminuted diminishing the potential for secure fixation with plate and screws alone. In the current study, we created a comminuted GT fragment to better account for what is truly observed in the clinical setting. This difference in methodological approach to fracture creation is the likely explanation for the observed discrepancies in the two studies.

There are several limitations to the present study. The proposed shoulder model was simplified: only the infraspinatus, supraspinatus and subscapularis muscles were loaded. The native motion of the shoulder is controlled by a more complex combination of dynamic and static stabilizers than our laboratory model takes into account. The compressive forces applied by the capsule and deltoid muscles may provide additional stability that was not replicated in this study. Motion in the current model was limited to internal and external rotation. Although these motions are important and represent physiologically relevant load magnitudes applied by the rotator cuff and experienced by the repair in the early postoperative period, motion in other planes such as abduction, adduction as 
well as flexion and extension may impart additional forces that warrant further study.

\section{Conclusion}

In conclusion, in this three-part proximal humerus fracture model, locked plating with suture augmentation of the rotator cuff significantly increased interfragmentary stability of the GT fragment compared to locked plate fixation alone. This study provides biomechanical evidence for reinforcing the GT fragment with sutures during locked plating of proximal humerus fractures.

\section{Source of Funding}

Research and institutional support was provided by Synthes. Synthes did not play any role in the research or in the preparation of this manuscript.

\section{References}

[1] Badman, B. and Mighell, M. (2008) Fixed-Angle Locked Plating of Two-, Three-, and Four-Part Proximal Humerus Fractures. Journal of the American Academy of Orthopaedic Surgeons, 16, 294-302. https://doi.org/10.5435/00124635-200805000-00008

[2] Gaheer, R. and Hawkins, A. (2010) Fixation of 3- and 4-Part Proximal Humerus Fractures Using the Philos Plate: Mid-Term Results. Orthopedics, 33, 671. https://doi.org/10.3928/01477447-20100722-11

[3] Nijs, S. and Broos, P. (2009) Outcome of Shoulder Hemiarthroplasty in Acute Proximal Humeral Fractures: A Frustrating Meta-Analysis Experience. Acta Orthopaedica Belgica, 75, 445-451.

[4] Lanting, B., et al. (2008) Proximal Humeral Fractures: A Systematic Review of Treatment Modalities. Journal of Shoulder and Elbow Surgery, 17, 42-54. https://doi.org/10.1016/j.jse.2007.03.016

[5] Solberg, B., et al. (2009) Locked Plating of 3- and 4-Part Proximal Humerus Fractures in Older Patients: the Effect of Initial Fracture Pattern on Outcome. Journal of Orthopaedic Trauma, 23, 113-119. https://doi.org/10.1097/BOT.0b013e31819344bf

[6] Mighell, M., et al. (2003) Outcomes of Hemiarthroplasty for Fractures of the Proximal Humerus. Journal of Shoulder and Elbow Surgery, 12, 569-577. https://doi.org/10.1016/S1058-2746(03)00213-1

[7] Brunner, F., et al. (2009) Open Reduction and Internal Fixation of Proximal Humerus Fractures Using a Proximal Humeral Locked Plate: A Prospective Multicenter Analysis. Journal of Orthopaedic Trauma, 23, 163-172. https://doi.org/10.1097/BOT.0b013e3181920e5b

[8] Sanders, B.S., et al. (2007) Biomechanical Evaluation of Locked Plating in Proximal Humeral Fractures. Journal of Shoulder and Elbow Surgery, 16, 229-234. https://doi.org/10.1016/j.jse.2006.03.013

[9] Seide, K., et al. (2007) Locked vs. Unlocked Plate Osteosynthesis of the Proximal Humerus-A Biomechanical Study. Clinical Biomechanics (Bristol, Avon), 22, 176182. https://doi.org/10.1016/j.clinbiomech.2006.08.009

[10] Weinstein, D.M., et al. (2006) Locking Plates Improve Torsional Resistance in the Stabilization of Three-Part Proximal Humeral Fractures. Journal of Shoulder and Elbow Surgery, 15, 239-243. https://doi.org/10.1016/j.jse.2005.08.006 
[11] Platzer, P., et al. (2008) Displaced Fractures of the Greater Tuberosity: A Comparison of Operative and Nonoperative Treatment. The Journal of Trauma, 65, 843-848. https://doi.org/10.1097/01.ta.0000233710.42698.3f

[12] Clavert, P., et al. (2010) Pitfalls and Complications with Locking Plate for Proximal Humerus Fracture. Journal of Shoulder and Elbow Surgery, 19, 489-494. https://doi.org/10.1016/j.jse.2009.09.005

[13] Antuna, S., et al. (2002) Shoulder Arthroplasty for Proximal Humeral Malunions: Long-Term Results. Journal of Shoulder and Elbow Surgery, 11, 122-129. https://doi.org/10.1067/mse.2002.120913

[14] Kettler, M., et al. (2006) Treatment of Proximal Humeral Fractures with the PHILOS Angular Stable Plate. Presentation of 225 Cases of Dislocated Fractures. Unfallchirurg, 109, 1032-1040. https://doi.org/10.1007/s00113-006-1165-7

[15] Voigt, C., et al. (2009) Additive Fiber-Cerclages in Proximal Humeral Fractures Stabilized by Locking Plates: No Effect on Fracture Stabilization and Rotator Cuff Function in Human Shoulder Specimens. Acta Orthopaedica, 80, 465-471. https://doi.org/10.3109/17453670903110659

[16] Voigt, C., et al. (2007) Management of Complications after Angularly Stable Locking Proximal Humerus Plate Fixation. Chirurg, 78, 40-46. https://doi.org/10.1007/s00104-006-1241-0

[17] Badman, B.L., et al. (2009) Proximal Humeral Nonunions Treated with Fixed-Angle Locked Plating and an Intramedullary Strut Allograft. Journal of Orthopaedic Trauma, 23, 173-179. https://doi.org/10.1097/BOT.0b013e31819b0bdc

[18] Fankhauser, F., et al. (2005) A New Locking Plate for Unstable Fractures of the Proximal Humerus. Clinical Orthopaedics and Related Research, 430, 176-181. https://doi.org/10.1097/01.blo.0000137554.91189.a9

[19] Konrad, G., et al. (2010) Open Reduction and Internal Fixation of Proximal Humeral Fractures with Use of the Locking Proximal Humerus Plate. The Journal of Bone and Joint Surgery, 92, 85-95. https://doi.org/10.2106/JBJS.I.01462

[20] Lee, C.W. and Shin, S.J. (2009) Prognostic Factors for Unstable Proximal Humeral Fractures Treated with Locking-Plate Fixation. Journal of Shoulder and Elbow Surgery, 18, 83-88. https://doi.org/10.1016/j.jse.2008.06.014

[21] Owsley, K.C. and Gorczyca, J.T. (2008) Fracture Displacement and Screw Cutout after Open Reduction and Locked Plate Fixation of Proximal Humeral Fractures. The Journal of Bone and Joint Surgery, 90, 233-240. https://doi.org/10.2106/JBJS.F.01351

[22] Ricchetti, E.T., Warrender, W.J. and Abboud, J.A. (2010) Use of Locking Plates in the Treatment of Proximal Humerus Fractures. Journal of Shoulder and Elbow Surgery, 19, 66-75. https://doi.org/10.1016/j.jse.2010.01.001

[23] Ring, D. (2007) Current Concepts in Plate and Screw Fixation of Osteoporotic Proximal Humerus Fractures. Injury, 38, 59-68. https://doi.org/10.1016/j.injury.2007.08.013

[24] Frankle, M., et al. (2002) Stability of Tuberosity Reattachment in Proximal Humeral Hemiarthroplasty. Journal of Shoulder and Elbow Surgery, 11, 413-420. https://doi.org/10.1067/mse.2002.126098

[25] Lin, C.L., et al. (2012) Suture Anchor Versus Screw Fixation for Greater Tuberosity Fractures of the Humerus-A Biomechanical Study. Journal of Orthopaedic Research, 30, 423-428. https://doi.org/10.1002/jor.21530

[26] Braunstein, V., et al. (2007) Operative Treatment of Greater Tuberosity Fractures of the Humerus-A Biomechanical Analysis. Clinical Biomechanics, 22, 652-657. 
https://doi.org/10.1016/j.clinbiomech.2007.03.002

[27] Ishak, C., et al. (2006) Fixation of Greater Tuberosity Fractures: A Biomechanical Comparison of Three Techniques. Bulletin (Hospital for Joint Diseases (New York, N. Y.)), 63, 98-99.

[28] Halder, A.M., et al. (2002) Biomechanical Comparison of Effects of Supraspinatus Tendon Detachments, Tendon Defects, and Muscle Retractions. The Journal of Bone and Joint Surgery, 84, 780-785. https://doi.org/10.2106/00004623-200205000-00013

[29] Veeger, H.E., et al. (1991) Inertia and Muscle Contraction Parameters for Musculoskeletal Modelling of the Shoulder Mechanism. Journal of Biomechanics, 24, 615-629. https://doi.org/10.1016/0021-9290(91)90294-W

[30] Wheeler, D.L. and Colville, M.R. (1997) Biomechanical Comparison of Intramedullary and Percutaneous Pin Fixation for Proximal Humeral Fracture Fixation. Journal of Orthopaedic Trauma, 11, 363-367. https://doi.org/10.1097/00005131-199707000-00012

[31] Neer 2nd, C.S., (1970) Displaced Proximal Humeral Fractures. I. Classification and Evaluation. The Journal of Bone and Joint Surgery, 52, 1077-1089.

https://doi.org/10.2106/00004623-197052060-00001

[32] Schliemann, B., et al. (2015) Screw Augmentation Reduces Motion at the Bone- Implant Interface: A Biomechanical Study of Locking Plate Fixation of Proximal Humeral Fractures. Journal of Shoulder and Elbow Surgery, 24, 1968-1973. https://doi.org/10.1016/j.jse.2015.06.028

[33] Brianza, S., et al. (2010) Biomechanical Evaluation of a New Fixation Technique for Internal Fixation of Three-Part Proximal Humerus Fractures in a Novel Cadaveric Model. Clinical Biomechanics, 25, 886-892. https://doi.org/10.1016/j.clinbiomech.2010.06.015

[34] Court-Brown, C.M., Garg, A. and McQueen, M.M. (2001) The Translated Two-Part Fracture of the Proximal Humerus. Epidemiology and Outcome in the Older Patient. The Journal of Bone and Joint Surgery, 83, 799-804. https://doi.org/10.1302/0301-620X.83B6.11401

[35] Keene, J.S., Huizenga, R.E. and Engber, W.D. (1983) Proximal Humeral Fractures: A Correlation of Residual Deformity with Long-Term Function. Orthopaedics, 6, 173-178.

[36] Mathews, J. and Lobenhoffer, P. (2004) Results of the Provision of Unstable Proximal Humeral Fractures in Geriatric Patients with a New Angle Stabilizing Antegrade Nail System. Unfallchirurg, 107, 372-380.

[37] Olsson, C. and Petersson, C.J. (2006) Clinical Importance of Comorbidity in Patients with a Proximal Humerus Fracture. Clinical Orthopaedics and Related Research, 442, 93-99. https://doi.org/10.1097/01.blo.0000194673.56764.0e

[38] Smith, A.M., et al. (2007) Early Complications of Operatively Treated Proximal Humeral Fractures. Journal of Shoulder and Elbow Surgery, 16, 14-24. https://doi.org/10.1016/j.jse.2006.05.008

[39] Vallier, H.A. (2007) Treatment of Proximal Humerus Fractures. Journal of Orthopaedic Trauma, 21, 469-476. https://doi.org/10.1097/BOT.0b013e318133479c

[40] Zyto, K., et al. (1997) Treatment of Displaced Proximal Humeral Fractures in Elderly Patients. The Journal of Bone and Joint Surgery, 79, 412-417. https://doi.org/10.1302/0301-620X.79B3.7419

[41] Zyto, K., Kronberg, M. and Brostrom, L.A. (1995) Shoulder Function after Displaced Fractures of the Proximal Humerus. Journal of Shoulder and Elbow Surgery, 


\section{4, 331-336. https://doi.org/10.1016/S1058-2746(95)80016-6}

[42] Badman, B., et al. (2011) Results of Proximal Humeral Locked Plating with Supplemental Suture Fixation of Rotator Cuff. Journal of Shoulder and Elbow Surgery, 20, 616-624. https://doi.org/10.1016/j.jse.2010.08.030

[43] Gardner, M.J., et al. (2007) The Importance of Medial Support in Locked Plating of Proximal Humerus Fractures. Journal of Orthopaedic Trauma, 21, 185-191. https://doi.org/10.1097/BOT.0b013e3180333094

[44] Smith, J., et al. (2004) Electromyographic Activity in the Immobilized Shoulder Girdle Musculature during Contralateral Upper Limb Movements. Journal of Shoulder and Elbow Surgery, 13, 583-588. https://doi.org/10.1016/j.jse.2004.03.010

\section{Submit or recommend next manuscript to SCIRP and we will provide best} service for you:

Accepting pre-submission inquiries through Email, Facebook, LinkedIn, Twitter, etc. A wide selection of journals (inclusive of 9 subjects, more than 200 journals)

Providing 24-hour high-quality service

User-friendly online submission system

Fair and swift peer-review system

Efficient typesetting and proofreading procedure

Display of the result of downloads and visits, as well as the number of cited articles Maximum dissemination of your research work

Submit your manuscript at: http://papersubmission.scirp.org/

Or contact ojo@scirp.org 